\title{
Expert consensus document: The International Scientific Association for Probiotics and Prebiotics (ISAPP) consensus statement on the definition and scope of prebiotics
}

\section{Article}

Published Version

Creative Commons: Attribution 4.0 (CC-BY)

Open Access

Gibson, G. R., Hutkins, R., Sanders, M. E., Prescott, S. L., Reimer, R. A., Salminen, S. J., Scott, K., Stanton, C., Swanson, K. S., Cani, P. D., Verbeke, K. and Reid, G. (2017) Expert consensus document: The International Scientific Association for Probiotics and Prebiotics (ISAPP) consensus statement on the definition and scope of prebiotics. Nature Reviews in Gastroenterology and Hepatology, 14. pp. 491-502. ISSN 1759-5045 doi: https://doi.org/10.1038/nrgastro.2017.75 Available at https://centaur.reading.ac.uk/75077/

It is advisable to refer to the publisher's version if you intend to cite from the work. See Guidance on citing.

To link to this article DOI: http://dx.doi.org/10.1038/nrgastro.2017.75

Publisher: Nature Publishing Group

All outputs in CentAUR are protected by Intellectual Property Rights law, 
including copyright law. Copyright and IPR is retained by the creators or other copyright holders. Terms and conditions for use of this material are defined in the End User Agreement.

\section{www.reading.ac.uk/centaur}

\section{CentAUR}

Central Archive at the University of Reading

Reading's research outputs online 


\section{CONSENSUS \\ STATEMENT}

OPEN

EXPERT CONSENSUS DOCUMENT

The International Scientific Association for Probiotics and Prebiotics (ISAPP) consensus statement on the definition and scope of prebiotics

Glenn R. Gibson', Robert Hutkins', Mary Ellen Sanders ${ }^{3}$, Susan L. Prescott ${ }^{4}$, Raylene A. Reimer ${ }^{5}$, Seppo J. Salminen ${ }^{6}$, Karen Scott ${ }^{7}$, Catherine Stanton ${ }^{8}$, Kelly S. Swanson ${ }^{9}$, Patrice D. Cani ${ }^{10}$, Kristin Verbeke ${ }^{11}$ and Gregor Reid ${ }^{12}$

Abstract | In December 2016, a panel of experts in microbiology, nutrition and clinical research was convened by the International Scientific Association for Probiotics and Prebiotics to review the definition and scope of prebiotics. Consistent with the original embodiment of prebiotics, but aware of the latest scientific and clinical developments, the panel updated the definition of a prebiotic: a substrate that is selectively utilized by host microorganisms conferring a health benefit. This definition expands the concept of prebiotics to possibly include non-carbohydrate substances, applications to body sites other than the gastrointestinal tract, and diverse categories other than food. The requirement for selective microbiota-mediated mechanisms was retained. Beneficial health effects must be documented for a substance to be considered a prebiotic. The consensus definition applies also to prebiotics for use by animals, in which microbiota-focused strategies to maintain health and prevent disease is as relevant as for humans. Ultimately, the goal of this Consensus Statement is to engender appropriate use of the term 'prebiotic' by relevant stakeholders so that consistency and clarity can be achieved in research reports, product marketing and regulatory oversight of the category. To this end, we have reviewed several aspects of prebiotic science including its development, health benefits and legislation.

Improving human health through modulation of the microbiome is an evolving strategy that is part of a comprehensive, holistic approach to lifestyle wellness ${ }^{1}$. The rich, diverse microbial ecosystems inhabiting mucosal and cutaneous surfaces provide targets for approaches to maintain or improve health or to treat disease. The ability to shift the composition and metabolic signatures of these microbial populations is now possible, via dietary or non-dietary interventions ${ }^{2,3}$.

Over 20 years ago, a class of compounds, termed prebiotics, were recognized for their ability to manipulate host microbiota to the benefit of the host ${ }^{4}$. At that time fructans (fructooligosaccharides (FOS) and inulin) and galactans (galactooligosaccharides or GOS) fit that category, with their effects acting through enrichment of Lactobacillus and/or Bifidobacterium spp. FOS and GOS currently dominate the prebiotic category as evidenced by numerous studies on their prebiotic effects.
Today, the prebiotic concept has expanded, in part, because of advances in tools for microbiome research (for example, high-throughput sequencing), which have improved our knowledge of the composition of the microbiota and enabled identification of additional substances influencing colonization. Concurrent with this progress is the realization that a broader range of beneficial microorganisms are affected by prebiotics and also that they might be effective at extraintestinal sites directly or indirectly ${ }^{5}$. Furthermore, the use of prebiotics has expanded to production and companion animals ${ }^{6,7}$ and categories beyond food. Accordingly, researchers have advocated for reconsideration of the contemporary nature of prebiotics, which formed the aim of the consensus panel that was convened on 9 December 2016 in London, UK. The various aspects looked at in this review of evidence were: evolution of the term prebiotic; effects and selectivity; substrates that 


\author{
Author addresses \\ ${ }^{1}$ Department of Food and Nutritional Sciences, The University of Reading, Whiteknights, \\ PO Box 226, Reading RG6 6AP, UK. \\ 2Department of Food Science and Technology, 258 Food Innovation Center, University of \\ Nebraska - Lincoln, Lincoln, Nebraska 68588-6205, USA. \\ ${ }^{3}$ International Scientific Association for Probiotics and Prebiotics, 7119S. Glencoe Court, \\ Centennial, Colorado 80122, USA. \\ ${ }^{4}$ School of Paediatrics and Child Health, The University of Western Australia, 35 Stirling \\ Highway, Perth, WA 6009, Australia. \\ ${ }^{5}$ Faculty of Kinesiology and Department of Biochemistry and Molecular Biology, \\ 2500 University Drive, Cumming School of Medicine, University of Calgary, Calgary, \\ Alberta, Canada. \\ ${ }^{6}$ Functional Foods Forum, Faculty of Medicine, Itäinen Pitkäkatu 4A, FI-20014, \\ University of Turku, Turku 20014, Finland. \\ ${ }^{7}$ Rowett Institute of Nutrition and Health, University of Aberdeen, Aberdeen, AB21 9SB, UK. \\ ${ }^{8}$ Teagasc Moorepark Food Research Centre, Fermoy, Cork, P61 C996, Ireland. \\ ${ }^{9}$ Department of Animal Sciences, University of Illinois at Urbana-Champaign, \\ 1207 W Gregory Drive, Urbana, Illinois 61801, USA. \\ ${ }^{10}$ Université catholique de Louvain, Louvain Drug Research Institute, 73 Avenue E Mounier, \\ WELBIO (Walloon Excellence in Life Sciences and Biotechnology), Metabolism and \\ Nutrition Research Group, 1200 Brussels, Belgium. \\ ${ }^{11}$ Translational Research in Gastrointestinal Disorders, KU Leuven, Targid - Herestraat 49, \\ Leuven, Belgium and Leuven Food Science and Nutrition Research Centre, BE 3001, \\ Leuven, Belgium. \\ ${ }^{12}$ Lawson Health Research Institute, University of Western Ontario, 268 Grosvenor Street, \\ London, Ontario, N6A 4V2, Canada.
}

are prebiotics; metabolism of prebiotics; host benefits; companion animals; and guidance for producers, consumers and regulators. Herein, the term 'microbiota' refers to the collection of microorganisms in an ecosystem and 'microbiome' when genetic elements are also considered.

\section{Methods}

A panel of experts was organized by the board of directors of the International Scientific Association for Probiotics and Prebiotics (ISAPP), a non-profit collaboration of scientists dedicated to advancing scientific excellence in probiotics and prebiotics. ISAPP activities are determined by the board of directors, comprising global academic scientists. Through its Industry Advisory Committee, ISAPP incorporates industry scientists in its activities and raises funds to advance its mission. However, no input into this consensus panel process was provided by members of the Industry Advisory Committee. ISAPP functions as an independent, objective, science-based voice for the probiotic and prebiotic fields.

Panellists included experts involved with the original development of prebiotics and subsequent modifications of the definition. Specialties included microbiology, nutrition, biochemistry and clinical research in both humans and animals. To prepare, panellists developed a discussion outline and target questions. Several delivered brief presentations that addressed background and core issues. Discussion ensued for each issue until consensus was achieved. After the meeting, individual panellists wrote sections of the summary, which were compiled by G.R.G., M.E.S and G.R. into a draft report. This document was edited and agreed upon by all panel members, and finally by the ISAPP board of directors.

\section{Evolution of the term prebiotic}

In 1921, Rettger \& Cheplin ${ }^{8}$ described experiments with humans whose microbiota were enriched with lactobacilli following consumption of carbohydrates. The finding that the colon was dominated by anaerobes, many of which obtain energy by fermenting substrates from the diet ${ }^{9,10}$, initiated research that played an important foundational part in many subsequent microbiome projects.

Although dietary oligosaccharides had long been used to impart health benefits, principally in Asia, the prebiotic concept was first defined in 1995 as a "nondigestible food ingredient that beneficially affects the host by selectively stimulating the growth and/or activity of one or a limited number of bacteria already resident in the colon" (REF. 4). The prebiotic concept was initiated to build on the probiotic concept, the most widely accepted definition of which was proposed in 2001 (REF. 11) and reaffirmed in 2014 (REF. 12). Prebiotics target humanassociated and animal-associated microbiota with the goal of improving health. Whereas probiotics use live microorganisms, prebiotics are non-viable substrates that serve as nutrients for beneficial microorganisms harboured by the host, including administered probiotic strains and indigenous (resident) microorganisms. Thus, prebiotics differ from most dietary fibres such as pectins, cellulose and xylans, which encourage growth of a wide variety of gut microorganisms. Our meaning here is that a prebiotic should not be broadly metabolized, but elicit a metabolism biased towards health-promoting microorganisms within the indigenous ecosystem. The review by Simpson and Campbell ${ }^{13}$ provides an overview of microbiota interactions and compares studies on fibre and prebiotics, concluding that prebiotics (particularly FOS and GOS) seem to promote increased abundance of bifidobacteria within the gut microbiota.

Most of the first prebiotics assessed in humans and used commercially were shown to stimulate Lactobacillus and Bifidobacterium specifically, but not pathogens such as certain members of the Clostridia class and Escherichia coli ${ }^{14-16}$. As these genera were commonly used as probiotics, this approach provided a commonality between probiotics and prebiotics. Thus, the prebiotic definition and the concept itself became imprinted in food, nutrition and microbiology fields ${ }^{17}$. In 2004, the definition of prebiotics was altered to "selectively fermented ingredients that allow specific changes, both in the composition and/or activity in the gastrointestinal microflora that confers benefits upon host well-being and health" (REF. 18). As per this definition, three criteria were required for a prebiotic: the ability to resist host digestion (for example gastric acidity, hydrolysis by mammalian enzymes and gastrointestinal absorption); that they are fermented by intestinal microorganisms; and that they selectively stimulate the growth and/or activity of intestinal bacteria associated with health and well-being. Thus, it was implicit that trials to demonstrate prebiotic effects should be performed in the target host. In vitro assessments designed to identify pathways or mechanisms would not confirm prebiotic status in the absence of studies providing evidence of health effects in the host. 
However, as prebiotic concepts evolved, so too did their application to extraintestinal sites. The Food and Agricultural Organization (FAO) of the United Nations (UN) organized a Technical Meeting to update the definition of prebiotics in 2008. This panel proposed that prebiotics be redefined as "a non-viable food component that confers a health benefit on the host associated with modulation of the microbiota" (REF. 19). Here, selective fermentation was removed as a criterion, but in doing so the definition was criticized for not excluding antibiotics. Gibson et al. ${ }^{20}, 2$ years later, defined the narrower category of 'dietary prebiotics' as "a selectively fermented ingredient that results in specific changes in the composition and/or activity of the gastrointestinal microbiota, thus conferring benefit(s) upon host health".

In 2015, Bindels et al. ${ }^{21}$ proposed that specificity requirements should be removed on the basis of reports showing that multiple taxa, rather than particular species, were enriched by prebiotics ${ }^{22}$. This proposal led to another definition of a prebiotic as "a non-digestible compound that, through its metabolization by microorganisms in the gut, modulates the composition and/or activity of the gut microbiota, thus, conferring a beneficial physiological effect on the host" (REF. 21). This definition limited prebiotics to interactions with the gut microbiota (excluding extraintestinal sites such as vagina and skin) and removed the requirement for selective fermentation. Selectivity with respect to microbial fermentation is viewed by this panel as key to the prebiotic concept. Importantly, however, this definition emphasized the functional effects of prebiotics on the microbiota.

Given the proposed definitions already described, as well as others, the need for a consensus definition was evi$\operatorname{dent}^{23}$. This need was amplified by views that the prebiotic concept required clarification on specificity, mechanisms of effect, health attributes and relevance, with some authors being critical of concepts already put forward and its approaches ${ }^{24-26}$. Thus, the current ISAPP consensus panel

\section{Box 1 | Main conclusions of the consensus panel regarding prebiotics}

- The definition of a prebiotic has been modified to 'a substrate that is selectively utilized by host microorganisms conferring a health benefit'

- Although most current prebiotics are administered orally, they can also be administered directly to other microbially colonized body sites, such as the vaginal tract and skin

- Health effects of prebiotics are evolving but currently include benefits to the gastrointestinal tract (for example, inhibition of pathogens, immune stimulation), cardiometabolism (for example, reduction in blood lipid levels, effects upon insulin resistance), mental health (for example, metabolites that influence brain function, energy and cognition) and bone (for example, mineral bioavailability), among others

- We acknowledge that definitive proof of causality is difficult to provide. However, a human or animal study showing a change in heath markers or symptoms after a specific influence on the microbial population (that is, a blinded placebo-controlled trial with appropriate exclusion and/or inclusion criteria) then it is reasonable to assume that the two are causally related

- Currently established prebiotics are carbohydrate-based, but other substances such as polyphenols and polyunsaturated fatty acids converted to respective conjugated fatty acids might fit the updated definition assuming convincing weight of evidence in the target host

- The beneficial effect(s) of a prebiotic on health must be confirmed in the target animal for its intended use and mediated through the microbiota now proposes the following definition of a prebiotic: a substrate that is selectively utilized by host microorganisms conferring a health benefit (BOX 1). See BOX 2 for additional rationale used to adopt this new definition.

\section{Prebiotic effect and selectivity}

Prebiotics are not the only substances that can affect the microbiota $^{10}$ (FIG. 1). The criterion of selective utilization distinguishes prebiotics from many of these other substances ${ }^{16}$. Hopefully, the new definition will readily enable a developer to know whether a new substrate fits the prebiotic category.

In previous iterations of the term prebiotic, 'selectively' was interpreted as referring mostly to lactobacilli and bifidobacteria. Specific stimulation of bifidobacteria (bifidogenesis) was considered a prebiotic effect. Early research on gut microbial ecology was based on culture methods, which we now know were insufficient to reveal the complexity of prebiotic-induced microbial changes. Molecular-based methods, which have since identified a broader range of members of the gut microbial community, have enabled the appreciation that more bacterial genera might utilize some prebiotic substrates, by fermentation and other metabolic pathways. These microorganisms can vary depending upon the host and ecosystem under consideration. Hence, it is recognized today that prebiotic effects probably extend beyond bifidobacteria and lactobacilli, but to meet the selectivity criterion of a prebiotic, the range of microorganisms affected must be limited. To this end, in two human studies that used high-throughput sequencing, bifidobacteria responded to prebiotic use $\mathrm{e}^{22,27}$. However, other groups such as Faecalibacterium prausnitzii also increased in abundance in one trial ${ }^{22}$ and in another study Anaerostipes spp. were additionally elevated, whereas Bilophila spp. decreased ${ }^{27}$. Both studies used high-throughput sequencing to confirm selectivity of the prebiotic fermentation. Selectivity does not necessarily mean effects on just one microbial group; a selective effect could extend to several microbial groups, just not all. A prebiotic, in addition to having a selective effect on microorganisms, must also evoke a net health benefit. The guiding principles are that microorganisms affected and metabolites produced are considered to be beneficial and linked to a defined health aspect.

Envisaging every scenario is challenging. But, for example, is a product a prebiotic if its intake increases microbial production of butyrate? Short-chain fatty acids (SCFAs), such as acetate, propionate and butyrate, and some other compounds, are recognized as having mechanistic links to health outcomes ${ }^{28,29}$. If the effect is a measurable benefit to host health, distinct from a control, it would constitute a 'prebiotic effect. To verify that the product itself is prebiotic, experiments would have to demonstrate that the product is selectively utilized, in this case by showing that a defined range of butyrateproducing microorganisms grow because of the product. Alternatively, the product might stimulate growth of other members of the microbiota, releasing metabolites that in turn stimulate butyrate production by other microorganisms. This phenomenon could constitute a 'cross-feeding effect.' The net result is still selective in that propagation of 


\section{CONSENSUS STATEMENT}

particular microorganisms led to this overall health effect. However, if pathogenic microorganisms are involved in butyrate generation and a negative consequence occurs for the host, then it cannot be termed a prebiotic. This distinction makes it important to determine both function and composition of the gut microbiota involved.

Similarly, prebiotics for use in the gut microbiota of humans should not form gas distension issues after ingestion; as such, their fermentation must be selective and preferably include genera that are not gas formers (such as Clostridium). This consideration points unequivocally towards the need for selective metabolism. Notably, neither bifidobacteria nor lactobacilli manufacture gas in their metabolism ${ }^{16}$.

Moreover, it is implicit that such influences on host health be determined in mixed microbial ecosystems containing the full microbiota of interest (that is, in vivo). Making inferences on prebiotic effects from pure or co-culture experiments is inadequate. Similarly, any conclusion regarding prebiotic activity must be based on an assessment of the full microbial diversity, not simply increased abundance of gut bifidobacteria or lactobacilli, for example. The best techniques available need to applied, particularly as the microbiome field has benefited greatly from molecular-based technological advances. These techniques would include highthroughput sequencing, including metagenomics, which demonstrates quantifiable changes in the microbiota.

\section{Box 2 | Justification for the new definition of prebiotics}

- It is a straightforward definition that avoids unnecessary technical jargon.

- It clarifies that prebiotic targets extend beyond stimulation of bifidobacteria and lactobacilli, and recognizes that health benefits can derive from effects on other beneficial taxa including (but not limited to) Roseburia, Eubacterium or Faecalibacterium spp.

- The term 'substrate' was chosen for its meaning of a substance on or from which an organism obtains its nourishment (for example, through fermentative breakdown of the substrate). This term aligns with the word 'utilized' and implies 'for growth through nourishment', therefore excluding viable microorganisms and antimicrobial agents as prebiotics.

- Prebiotics rely upon microbial metabolism. Non-microbial effects do not fit with our current classification. For the latter, these effects have tended to be researched in situations in which a resident microbiota is devoid or compromised. To confirm prebiotic traits, studies in the same species as the intended use are required.

- Prebiotics require selective utilization by live host microorganisms, not simply enzymes or bioactive chemicals, in a manner that sustains, improves or restores host health. Although many microorganisms might be able to breakdown a given substrate, it is the resultant health benefit to the host owing to selective utilization by microorganisms that enables it to be termed prebiotic. The actual mechanism of conferring benefit might also be mediated by microbial metabolic products. As such, both the microbiota changes and metabolites should be investigated, together with health outputs.

- It allows a prebiotic to invoke changes to any host microbial ecosystem, not just the gut. However, dietary prebiotics should still be non-digested by the host but utilized by the microbiota.

- Both prebiotic safety and use at appropriate dose are implicit in this definition. An appropriate dose must be sufficient to generate a prebiotic effect, but not too high to induce unwanted or adverse effects such as excessive gas formation or non-selective utilization. The 'adequate' dose will vary depending upon the microbial ecosystem and associated metabolic effects.

- Demonstration of health benefits in well-controlled studies in the target host is required.
Similarly, metabonomic assessments, such as NMR or mass spectrometry, in appropriate biological materials can identify metabolic responses to prebiotics and help determine concomitant functionality of the microbiota.

\section{Substrates that are prebiotics}

A number of fermentable carbohydrates have been reported to convey a prebiotic effect, but the dietary prebiotics most extensively documented to have health benefits in humans are the non-digestible oligosaccharides fructans and galactans ${ }^{30}$. These oligosaccharides are preferentially metabolized by bifidobacteria ${ }^{16}$. A phenomenon explained by structure to function relationships; the linkage bonds in FOS and GOS can be readily degraded by degraded by $\beta$-fructanosidase $\beta$-galactosidase enzymes, respectively, which are prevalent in bifidobacteria. This genus also seems to preferentially metabolize the chain length size typical of oligosaccharides; that is, a degree of polymerization (DP) between 4 and 30 (REFS 31,32). Importantly, having the appropriate transport machinery to capture and deliver these substrates into the microbial cytoplasm is a key requirement and contributes to the selectivity of prebiotics in the target sites ${ }^{33}$ and emphasizes their ability to do so in a competitive environment in mixed culture ecosystems such as the human gut.

Substrates that affect composition of the microbiota through mechanisms not involving selective utilization by host microorganisms are not prebiotics. These substrates would include antibiotics, minerals, vitamins and bacteriophages, which are not growth substrates, even though their intake might alter microbiota and metabolic composition.

Certain soluble fermentable fibres are candidate prebiotics $^{34}$, and some other types of dietary fibre can be prebiotic, provided that they are selectively utilized by the host microbiota and promote health. Categorizing fibres as prebiotics is complicated by the fact that a dietary fibre can be a prebiotic in one host but not another. For example, cellulose can be considered a prebiotic in ruminants but not in humans, as the latter's intestinal microbiota only poorly utilize $\beta(1 \rightarrow 4)$ linked D-glucose polysaccharides $^{35}$. Furthermore, a substrate qualifying as a prebiotic might also depend on the target site. For example, xylitol can be considered as a prebiotic in the oral cavity, but has not been shown to be prebiotic elsewhere ${ }^{16,18}$.

Among the first group of substances recognized for their ability to influence gastrointestinal health were the oligosaccharides present in human milk. Human milk oligosaccharides (HMOs) are particularly important for the development of the newborn baby's intestinal microbiota and metabolic and immunological systems, which have consequences for health later in life $\mathrm{e}^{36,37}$. Consumption of mother's milk containing these HMOs clearly increases the proportion of HMO-consuming Bifidobacteriaceae and Bacteroidaceae ${ }^{28}$. Bifidobacterium longum subsp. infantis (B. infantis) is the only Bifidobacterium spp. that has specifically evolved machinery to degrade the complete repertoire of HMOs. Other Bifidobacterium spp. predominant in adults, mainly B. longum subsp. longum, $B$. adolescentis and B. lactis, lack many of the enzymes necessary to directly utilize HMOs effectively ${ }^{38,39}$. 


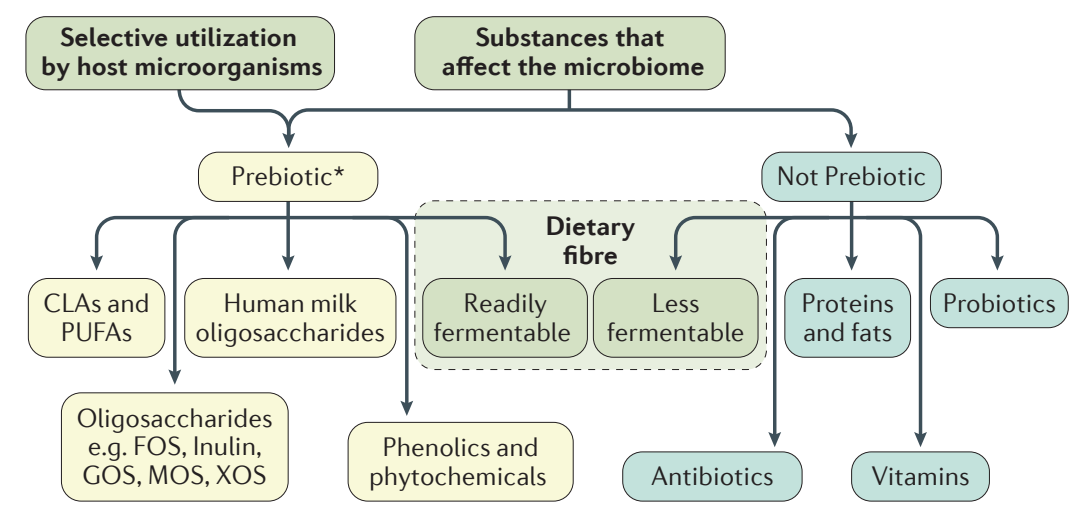

Figure 1 | Distinguishing what is considered a prebiotic with the proposed definition. Prebiotics must be selectively utilized and have adequate evidence of health benefit for the target host. Dietary prebiotics must not be degraded by the target host enzymes. *The figure shows candidate as well as accepted prebiotics in that levels of evidence currently vary, with FOS and GOS being the most researched prebiotics.CLA, conjugated linoleic acid; PUFA, polyunsaturated fatty acid; FOS, fructooligosaccharides; GOS, galactooligosaccharides; MOS, mannanoligosaccharide; XOS, xylooligosaccharide.

HMOs might indirectly affect composition of the intestinal microbiota by modulating immune responses and also have metabolism-independent mechanisms of action in the infant gut ${ }^{40}$. In particular, fucosylated and sialylated HMOs can prevent adhesion of pathogens to the intestinal epithelium through a competitive mechanism that ultimately protects the neonate from infection ${ }^{41,42}$. The main issues for this discussion are the following. Is there evidence that HMOs confer a health benefit in humans through the host's microbiota selectively utilizing them, and therefore fulfilling the prebiotic definition? And if compounds equivalent to HMO (or bovine milk oligosaccharides, BMOs) were to be produced by enzymatic synthesis, fermentation or extraction, could they still be considered as prebiotic?

The ability of HMOs, BMOs or synthesized compounds to act as a substrate for the selective growth of beneficial bacteria, such as Bifidobacterium spp., would be supportive evidence of a prebiotic nature ${ }^{43}$. To confirm their status as a prebiotic, a controlled human study showing selective growth of bifidobacteria resulting in a health benefit is also needed. However, the use of such compounds for in vivo studies is limited to only a few reports. In one study, a chemically synthesized compound, 2 '-fucosyllactose ( $\left.2^{\prime} \mathrm{FL}\right)$, equivalent to the naturally occurring $2^{\prime} \mathrm{FL}$ in $\mathrm{HMO}$, was added to formula milk along with GOS. Although safe for infants, the 2'FL treatment provided no net difference in weight, length, head circumference and other measures compared with human milk over a 4-month period $^{44}$. In another study by the same group, infants fed formula with 2 'FL plus GOS had immune responses similar to breast-fed infants in that both groups had lower levels of inflammatory cytokines than infants fed formula plus GOS ${ }^{45}$. However, effects on the microbiota were not reported in this study. In a third study, 2'FL and another synthesized HMO, lacto- $N$-neotetraose, were administered to adults ${ }^{46}$. The treatments were well tolerated and led to an increase in abundance of Bifidobacterium spp. Collectively, these studies provide an incomplete assessment of the prebiotic properties of these synthesized versions of HMOs. Although 2'FL is utilized by B. infantis as well as some strains of B. longum subsp. longum and B. breve ${ }^{46,47}$, the ecological context (that is, infants versus adults) might dictate whether these HMOs are indeed prebiotic. Moreover, having structural equivalence to specific HMOs does not infer functional equivalence to the constellation of HMOs in milk ${ }^{48}$. Thus, for now, it is acceptable to state that some HMOs are candidate prebiotics.

Plant polyphenols constitute a class of compounds that can also meet the criteria of prebiotics, although far more studies in the target host are required. An estimated $90-95 \%$ of dietary polyphenols are not absorbed in the small intestine and, therefore, reach the colon ${ }^{49}$ where they undergo extensive biotransformation by the colonic microbiota. Increasing evidence indicates that health benefits associated with polyphenol consumption depend on microbial utilization and the metabolites produced, rather than on parent compound $s^{50}$.

This evidence expands the prebiotic concept beyond non-digestible oligosaccharides such as FOS and GOS. However, evidence for these emerging prebiotics is scarce relative to the fructans and galactans ${ }^{16}$ and more studies measuring health benefits are required to fulfil their prebiotic status.

\section{Prebiotic utilization and host health}

As selective utilization of a prebiotic by host microorganisms is key to its physiological effects, metabolic results of this utilization must, by deduction, be the main drivers. Some organic acids, for example, are principal end products of non-digestible carbohydrate or dietary fibre fermentation by host microorganisms. The main SCFAs $(\geq 95 \%)$ generated mostly in the colon (humans) and caecum (rodents) as a result of several bacterial metabolic pathways are acetate (two carbon, C2), propionate (C3)) and $n$-butyrate (C4). These SCFAs are crucial for intestinal health and their activity can subsequently influence sites distant to the gut, with different SCFAs having varying functions. SCFAs can modulate certain aspects of metabolic activity including colonocyte function, gut homeostasis, energy gain, the immune system, blood lipids, appetite and renal physiology, as reviewed elsewhere ${ }^{16,51,52}$.

In a study published in $2017,{ }^{13} \mathrm{C}$-labelling was used to show that colonic-administered acetate, propionate and butyrate were systemically available at 36\%, $9 \%$ and $2 \%$, respectively, with conversion of acetate into butyrate (24\%) by the colonic microbiota ${ }^{53}$. Bifidobacteria, often stimulated by specific prebiotics, do not produce butyrate, so a probable scenario is that cross-feeding by other bacteria must have resulted in production of this SCFA. Much has been reported about the benefits of butyrate in the gut and beyond ${ }^{54}$, leading to the potential of known butyrate producers such as Faecalibacterium prausnitzii, Eubacterium rectale or Roseburia spp. as possible probiotics and, therefore, new prebiotic targets. By contrast, in the vagina, butyrate formation is more equivocal as 2 -hydroxyisovalerate and $\gamma$-hydroxybutyrate have been associated with bacterial vaginosi ${ }^{55}$. Rather, lactic acid production and an increase in IL-10 levels might be beneficial, indicating that prebiotics might be functional in the vaginal environment, because of their effects in 
the gut ${ }^{56}$. Lactulose, which has potential benefits in the gut and vagina, can increase lactic acid levels and decrease $\beta$-glucuronidase activity, considered beneficial for the host $^{57}$. Owing to the anatomical proximity of rectum to vulva, some microorganisms capable of utilizing prebiotics in the gut are also present in the vagina, including Bifidobacterium and Lactobacillus spp. ${ }^{58-60}$.

Bile salt hydrolases are a family of enzymes produced exclusively by enteric microorganisms as a form of defence against their harsh, bile-rich environment. Bile acid transformation and/or metabolism in the gut is performed by a number of species, including Lactobacillus, with known beneficial effects on the host. Joyce \& Gahan ${ }^{61}$ demonstrated that elevated bile salt hydrolase activity could promote reduced weight gain in mice and influence host pathways involved in lipid metabolism, peripheral circadian rhythm, gut barrier function and immune homeostasis. One study ${ }^{62}$ showed that enhanced bacterial deconjugation of taurine from primary bile acids occurred in the presence of prebiotic inulin, supporting the theory that faecal bile acid profiling might be a useful biomarker for the intake of prebiotics in mice and potentially also in humans.

The net result of prebiotic utilization within the gut could also extend to health benefits elsewhere in the body. For example, GOS stimulated growth of bifidobacteria in the mouse gut led to modulation of cortical $\mathrm{IL}-1 \beta$ and $5-\mathrm{HT}_{2 \mathrm{~A}}$ receptor expression and reduced anxiety levels ${ }^{63}$, as well as enhancing brain barrier function in obese mice ${ }^{64}$. Similarly, utilization of prebiotics might also reduce blood ammonia levels and improve psychometric tests in patients with hepatic encephalopathy ${ }^{65}$, presumably through the formation of relevant bacterial metabolites. Study findings suggest that prebiotics can reduce the development or severity of atopic dermatitis and eczema in children, presumably mediated by alterations to bacterial growth and interactions with the developing immune system, beginning in the gut ${ }^{66,67}$. The ability to increase water retention on the skin and reduce erythema formation is an emerging attribute of GOS ingestion, as reported in mouse studies ${ }^{68}$. On the skin, application of a prebiotic might stimulate changes in bacterial ${ }^{69}$ or fungal ${ }^{70}$ profiles perhaps by targeting epidermal growth factor receptor. The health consequences of this approach are currently unclear, but might include psoriasis, acne, dermatitis, eczema and wound development ${ }^{66,67,71}$.

Studies in mice have shown that oligofructose (a fruc$\tan )$ reduced diet-induced obesity, diabetes, hepatic steatosis and inflammation by mechanisms linked with changes in specific gut microorganisms and metagenomics functions of bacteria ${ }^{72}$. A study in rats suggested that oligofructose consumption might normalize the metabolomic signature of insulin resistance in obese rats and reduce obesity in offspring ${ }^{73}$. The ability to enhance secretion of satiety hormones peptide YY and glucagonlike peptide-1 might be an associated attribute of prebiotic intervention and related SCFA production ${ }^{74-76}$.

In the mouth, compounds such as algal lectins, cranberry juice and cocoa polyphenols have been used to reduce the abundance of cariogenic bacteria. However, these substrates do not function through being selectively utilized by beneficial host microorganisms in the mouth, so they are not prebiotics ${ }^{77}$. Short-chain GOS and longchain FOS have been administered orally with $B$. breve and were found to increase peak expiratory flow and reduce systemic production of type $2 \mathrm{~T}$-helper cytokines after allergen challenge in adults with allergic asthma ${ }^{78}$. The proposed mechanism, whereby microbial utilization of GOS and FOS, presumably in the intestine, could lead to immunological modulation that enabled the host to cope better with allergen exposure in the lungs, was not identified. In the nose and upper respiratory tract, bacterial species can be manipulated by prebiotics to influence health through immune reactions ${ }^{79}$ or competition with aetiological agents of disease ${ }^{80}$.

\section{Conferring a health benefit}

The ultimate goal of any intervention, including prebiotics, is to improve health and, therefore, reduce the risk or burden of disease. The most effective approaches are those that rely on prevention and recognize that early-life strategies that promote a resilient, diverse and healthy microbiota have greatest long-term potential to benefit health ${ }^{81,82}$. Evidence for the important relationship between the structure and function of the microbial community, prebiotic use and host health has accumulated rapidly over the past decade ${ }^{20,23,30}$. To satisfy the criterion of conferring a health benefit, controlled studies establishing direct links between the prebiotic and health are needed in the target host. The level of evidence should be commensurate with the strength of the health benefit claim. To date, numerous randomized controlled trials have shown health benefits of a variety of prebiotics across a range of populations, from healthy individuals to those with acute and chronic diseases. These and other human studies have been summarized elsewhere and are not discussed in detail here, but key examples are listed in TABLE 1 (REFS 16,65,67,83-120).

Importantly, the effects of any intervention will be affected by a variety of host and environmental factors ${ }^{121}$. Thus, the effects of prebiotics have the potential to vary widely on an individual basis. Microbial utilization of prebiotics can only occur if the appropriate bacteria are a component of the host's microbiota. This aspect might explain individual differences in responsiveness and in the outcomes of clinical trials. Host factors include variation in genetic predisposition to diseases (across multiple loci) as well as specific polymorphisms in microbial recognition pathways that can influence colonization and its biological effects $^{16}$. A number of environmental factors, including mode of delivery and early feeding, antibiotics, disease status and adult diet, can influence the human microbiome and possibly the effects of prebiotic supplementation ${ }^{122-125}$.

\section{Application to benefit animals}

Prebiotics have been studied and used for companion animals, livestock, poultry and aquaculture. The inherent differences among animal species with regards to living environment, anatomy and physiology, dietary composition and reliance on the gut microbiota for energy, must be considered when evaluating the effect of prebiotics on animal health ${ }^{126}$. 
Table 1 | Health end points targeted in human trials of orally administered prebiotics

\begin{tabular}{|c|c|c|}
\hline Health end point & Prebiotic used & Refs \\
\hline $\begin{array}{l}\text { Metabolic health: overweight and obesity; type } 2 \text { diabetes mellitus; } \\
\text { metabolic syndrome and dyslipidaemia; inflammation }\end{array}$ & Inulin, GOS, FOS & $22,74,75,83-90$ \\
\hline Satiety & FOS & $75,76,90-92$ \\
\hline Stimulation of neurochemical-producing bacteria in the gut & GOS & 93,94 \\
\hline Improved absorption of calcium and other minerals, bone health & Inulin, FOS & $95-99$ \\
\hline Skin health, improved water retention and reduced erythema & GOS & 100,101 \\
\hline Allergy & FOS, GOS & $102-105$ \\
\hline IBD & Inulin, lactulose & 106 \\
\hline Urogenital health & GOS & 107 \\
\hline Bowel habit and general gut health in infants & GOS, FOS, & 108,109 \\
\hline Infections and vaccine response & FOS, GOS, polydextrose & $110-114$ \\
\hline Necrotizing enterocolitis in preterm infants & GOS, FOS & 115 \\
\hline IBS & GOS & 116 \\
\hline Traveller's diarrhoea & GOS & 117 \\
\hline Constipation & Inulin & 118,119 \\
\hline Immune function in elderly individuals & GOS & 56,120 \\
\hline
\end{tabular}

TABLE 2 provides examples of the use of prebiotics in animals. Dogs and cats evolved as Carnivora eating diets high in protein and fat but low in fibre ${ }^{126}$. They are nonruminants with short, simple gastrointestinal tracts that have little capacity to ferment non-digestible substances, which predominantly occurs in the colon ${ }^{126}$. Nevertheless, some health benefits have been achieved with prebiotic administration such as reduced infections, improved insulin sensitivity and better faecal consistency ${ }^{127-131}$.

Prebiotics such as oligosaccharides of fructose, mannose and chitin protect piglets against high environmental stressors (such as antibiotics, etc.) and pathogen loads, including faecal E. coli shedding, and reduced infection-associated responses to Salmonella enterica serovar Typhimurium infection or porcine reproductive and respiratory syndrome virus ${ }^{132-135}$.

Calves are born in a pre-ruminant state and function as non-ruminants until the rumen and other compartments of the stomach fully develop ${ }^{136}$. During the first few weeks of life, or longer in the case of veal calves maintained on low-roughage diets (that is, low in fibrous material), prebiotics can be used to increase growth, improve feed conversion ratio, reduce the incidence and severity of scours (diarrhoea) or reduce the incidence of respiratory diseases ${ }^{136-139}$.

Poultry, which are used primarily for the production of meat or eggs, include landfowl (for example, chickens, turkeys and quail) and waterfowl (for example, duck or geese) species, respond to prebiotics despite most having a fairly short midgut and hindgut that includes a short, straight colon and twin caeca ${ }^{140}$. Dietary prebiotics, including inulin, yeast cell wall extracts, lactulose and GOS are usually fed at concentrations up to $0.2 \%$ (weight/volume) of diet $^{140-146}$.

Farmed aquatic species include finfish and shellfish. Although anatomy varies among carnivorous (for example, turbot), omnivorous (for example, catfish) and herbivorous (for example, sturgeon) species, all fish have a fairly simplistic and short gastrointestinal tract ${ }^{147-149}$. The short length and simple structure (lack of special adaptations) of the fish gut results in the rapid transit of digested material, limiting the time available for microbial or prebiotic activity. Effective prebiotic doses in aquatic host species are typically in the range of $1-3 \%$ (weight/volume) of $\operatorname{diet}^{147-149}$.

Horses are large non-ruminant herbivores that rely heavily on microbial fermentation for energy, with more than half of their maintenance energy requirement coming from microbial fermentation occurring in their enlarged caecum and colon ${ }^{126}$. As their typical diet is high in roughage and feedstuffs that are consumed throughout the day, prebiotic interventions might help improve effectiveness of fermentation ${ }^{150-152}$.

\section{Guidance for stakeholders}

Developing a consensus definition of prebiotic is useful for many stakeholders (FIG. 2), whose responsibilities are discussed here. Agreement on this definition will reduce misinformation and confusion among consumers and health-care providers, facilitate sensible regulatory approaches, and provide common terminology and scope for future prebiotic research.

Consumers. This consensus definition should enable consumers to understand the terms used on product labels. Proper use of the terms by all stakeholders will help avoid misleading messaging. Although consumers might not be expected to understand the mechanistic details for how prebiotics function to improve health, our proposed definition should be readily appreciated. Individuals can respond variably (due to their habitual diets, host microbiota, host genetics) to different 


\section{CONSENSUS STATEMENT}

\section{Table 2 | Use of prebiotics in animals}

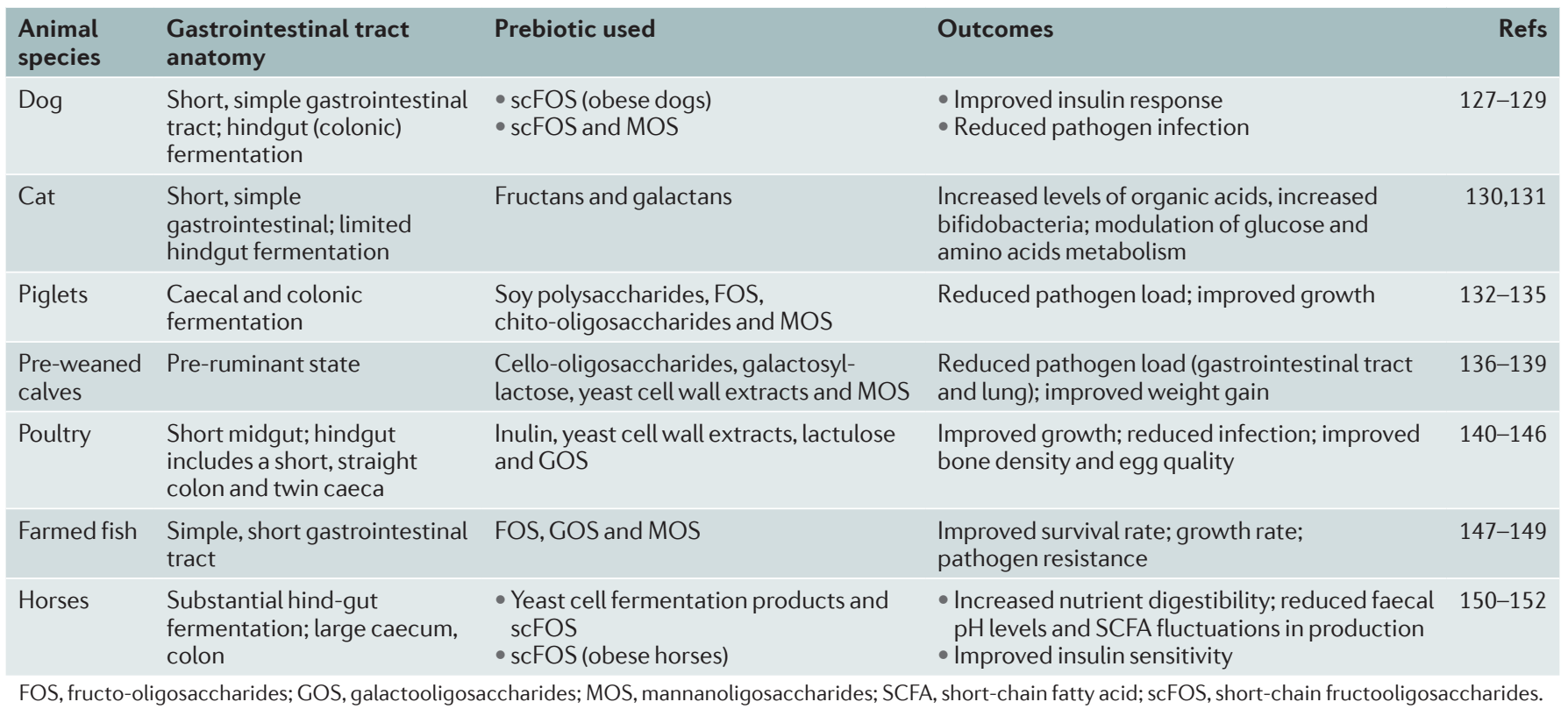

prebiotics. This aspect dovetails with the concept of individualized nutrition, which should be understood by consumers.

Media and publishers of scientific papers. The media (press, TV, web-based and others) should avoid use of headlines that misrepresent results. Presentation of association studies as if they contribute to an understanding of causality can be especially misleading. When discussing results of a single study, how that study fits into the totality of evidence for that topic should be reported, including null results. The media should use the term prebiotic consistent with this proposed definition.

Regulators. Regulators have primary responsibility for ensuring safety of marketed products and protecting consumers from fraudulent marketing. To accomplish these goals, they are bound by statutes and regulations adopted in their respective regions. Acceptance by regulators of the consensus definition of prebiotic would make it clear what can be expected of these substances from a scientific basis, and whether the term is being used appropriately. For example, most prebiotics for the gut require an oral dose of upwards of $3 \mathrm{~g}$ per day to elicit an effect ${ }^{16}$. Products containing doses lower than this level should not be called prebiotics, unless such a low dose has been proven to elicit selective effects upon the microbiota and concomitant health aspects. Incorporating a health benefit in the definition gives a tangible end point for producers and regulators alike to use in their assessment of whether a novel product fulfils the criteria.

Scientists. Scientists have the responsibility of considering all aspects of research on prebiotics (structural biochemistry, clinically relevant end points, effective dose, mechanisms of action, analytical methods) and consolidating findings such that a clear description of outcomes can be attained. Future prebiotic research should strive to confirm causality between an observed health benefit and microbiota-mediated mechanisms. This confirmation of causality has been challenging to achieve and some assumptions might be necessary, as is the case for most pharmaceutical interventions. To this end, well-controlled, placebo, blinded in vivo studies that exploit the latest multi-omic technologies are necessary. For example, in the case of a dietary prebiotic for humans, a full assessment of gut microbiota changes using robust molecular procedures that are fully and accurately quantifiable is required, such that selective substrate use can be ascertained. This analysis would be coupled with metabolic assessments of functionality (for example, metabonomics applied to blood, urine and faeces). In patients, symptomology should be determined, and in healthy or 'at-risk' populations reliable biomarkers of beneficial effects must be identified and measured. These biomarkers could include immunological changes, inflammatory mediators, serum lipid levels, genotoxicity, toxicity and cognitive function, among others, as appropriate to the study population. The study population must be reflective of the condition being researched, and an appropriate power calculation used to determine volunteer numbers. An effective prebiotic dose and duration must be established to compare effects. The test delivery vehicle (for example, foods such as cereal, bread or juices) should be considered such that prebiotic potential is not compromised. Exclusion and inclusion criteria are applied to control for fluctuations in diet and other major lifestyle changes. Following that, if the only discernible correlation is an improvement in health indices with selective microbiota changes (composition and function) then it could be assumed that two are inter-related and driven 
by the prebiotic. When communicating results, scientists should be careful to present data in a manner that does not mislead readers.

Suppliers or manufacturers of prebiotics. Suppliers and manufacturers have the responsibility to accurately characterize the identity of their prebiotics and conduct research to evaluate health benefits and safety. They should be committed to high-quality, controlled, nonbiased studies that assess effects on clinically relevant outcomes with associated peer-reviewed publication of the findings. They need to provide accurate technical information to end-product manufacturers.

End-product manufacturers. Producers of consumer products have a special responsibility to formulate and label prebiotic products in a manner that is true to the definition proposed herein, does not overstate the strength of evidence for health benefits and is consistent with dose and form used in efficacy studies. Producers can contribute by sponsoring research on health benefits of their final products. Advertising must be consistent with scientific definitions, not overstate the strength of evidence for health benefits and adhere to regulatory standards.

Health-care providers and standards or recommendationsetting organizations. By providing compelling data that prebiotics can improve health, it is hoped that clinical organizations will accept and use the new definition, review the data in totality and develop evidence-based recommendations. This approach will help health-care providers to make decisions about clinical use in the absence of formal recommendations (based upon their own risk-benefit analysis).

\section{Further regulatory considerations}

We anticipate that future prebiotic products will expand current applications, include products administered to many body sites and be developed as non-conventional (or novel) foods, pharmaceuticals or other categories. In this section further insights into regulatory considerations in two jurisdictions are provided as examples, but the way that prebiotics are regulated will differ in other countries.

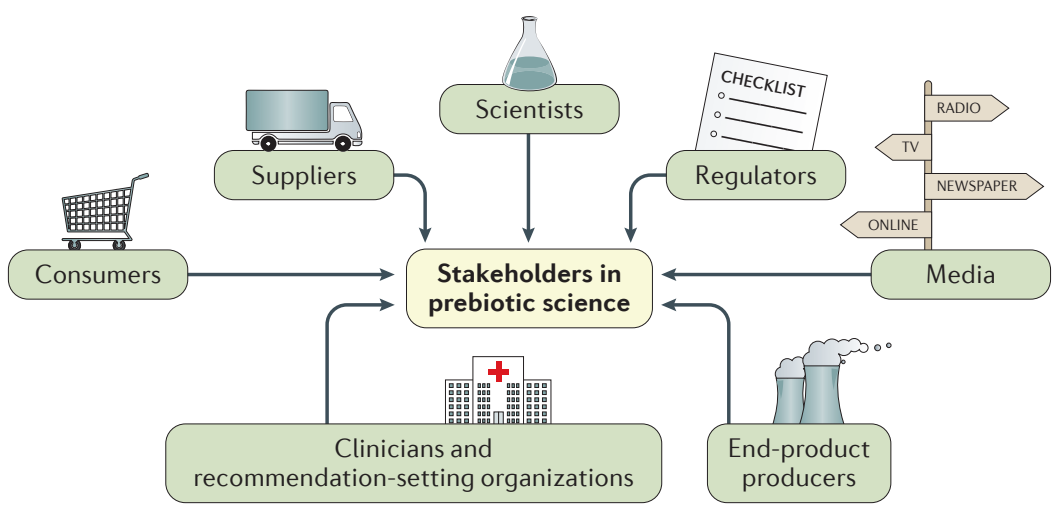

Figure 2 | Stakeholders with an interest in prebiotic science.
European Union. In the European Union (EU), any health message carried by food requires assessment of the science by the European Food Safety Authority (EFSA) and authorization by the European Commission. Some prebiotic health claims have been approved, for example chicory inulin ${ }^{153}$.

Inulin, FOS and GOS were used in the EU before 1997 and are considered safe food ingredients. However, prebiotic substances created after 1997 are considered novel and require safety clearance, a designation given, for example, to specific HMOs. To date, only one prebiotic, chicory inulin, has received an EU health claim: "Inulin improves bowel function" (REF. 153). This approval was based on demonstration of a cause-effect relationship between consumption of the non-fractionated mixture of monosaccharides ( $<10 \%$ of total carbohydrate), disaccharides, inulin-type fructans and inulin extracted from chicory with a mean DP $\geq 9$, and maintenance of normal defecation by increasing stool frequency. Additional product approvals hopefully will be forthcoming, once relevant evidence is available, aided by the contents of this consensus document.

When prebiotics are considered to be novel foods, challenges arise to assessments as a food or individual ingredient. The EU considers HMOs added to a food as novel food ingredients, a legal construct determined by law ${ }^{154}$. A FOS or GOS with a markedly altered DP or with a different source or production method might be regarded as a novel food. An additional factor in the EU is the new consideration of safe history of use in countries outside the $\mathrm{EU}^{154}$.

USA. Prebiotics is not yet a term recognized by the FDA. Prebiotics are regulated based on the category of product their intent and design dictates. Most prebiotics are sold as ingredients for foods (including infant formula) or are dietary ingredients in dietary supplements. The FDA issued an updated guidance to industry on the new dietary ingredient notification process in 2016 (REF. 155). Other regulatory categories that might apply to prebiotics are medical foods, drugs, cosmetics or devices developed for humans or animals. Changes to fibre labelling regulations in the USA in 2014 (in part owing to the different methods of analysis of fibre worldwide) will probably affect carbohydrate-based prebiotics ${ }^{156}$.

In the past, various analytical methods determined fibre levels in foods. Prebiotics, detected as soluble fibre, could be listed as fibre on the nutrition facts label. Under the new regulations, this listing will not be allowed. Fibre has been redefined to be soluble and insoluble non-digestible carbohydrates (with three or more monomeric units) and lignin that are intrinsic and intact in plants, and certain isolated and synthetic non-digestible carbohydrates (with three or more monomeric units). Some prebiotics, such as inulin, fall under the latter category, but even so were not granted status as a fibre by the FDA. The new rules require that for a prebiotic to be listed as fibre, it must confer a beneficial physiological effect and this evidence must be submitted to the FDA either though the citizen 
petition process or the health claims petition process for the FDA to authorize the health claim. The FDA has promised further guidance on this topic.

\section{Conclusions}

This paper describes conclusions of a consensus panel of experts regarding a definition of prebiotic and the rationale for that definition. It is hoped that this new definition and explanation will clarify what is required to call a substance a 'prebiotic'. Given that differences exist across animal species, prebiotic efficacy, safety and appropriate dosing should be demonstrated for the specific target host.
In conclusion, prebiotics have the potential to improve human and animal health and reduce risk of diseases mediated by microbiota aberrations. The field would greatly benefit from research focused on mechanisms of action, characterizing responders or non-responders, understanding how structure relates to function of prebiotic substances and correlating that function to health outputs. The use of prebiotics to improve health cannot be, and should not be, viewed in isolation, and will be part of a wider approach for healthy nutrition and lifestyle. The capacity exists for prebiotics to be used therapeutically in the management of disease and to preventively promote health.
1. Prescott, S. L., Logan, A. C., Millstein, R. A. \& Katszman, M. A. Biodiversity, the human microbiome and mental health: moving toward a new clinical ecology for the 21 st Century? Int. J. Biodiversity 2016, 2718275 (2016).

2. David, L. A. et al. Diet rapidly and reproducibly alters the human gut microbiome. Nature 505, 559-563 (2014).

3. Cani, P. D. \& Everard, A. Talking microbes: when gut bacteria interact with diet and host organs. Mol. Nutr Food Res. 60, 58-66 (2016).

4. Gibson, G. R. \& Roberfroid, M. B. Dietary modulation of the human colonic microbiota: introducing the concept of prebiotics. J. Nutr. 125, 1401-1412 (1995).

5. Collins, S. \& Reid, G. Distant site effects of ingested prebiotics. Nutrients 8, E523 (2016).

6. Propst, E. L. et al. A dose-response experiment evaluating the effects of oligofructose and inulin on nutrient digestibility, stool quality, and fecal protein catabolites in healthy adult dogs. J. Anim. Sci. 81, 3057-3066 (2003).

7. Park, S. H., Lee, S. I. \& Ricke, S. C. Microbial populations in naked neck chicken ceca raised on pasture flock fed with commercial yeast cell wall prebiotics via an Illumina MiSeq platform. PLOS ONE 11, e0151944 (2016).

8. Rettger, L. F. \& Cheplin, H. A. A. Treatise on the Transformation of the Intestinal Flora: with Special Reference to the Implantation of Bacillus acidophilus Vol. 13 (Yale Univ. Press, 1921).

9. Dubos, R. et al. Indigenous, normal, and autochthonous flora of the gastrointestinal tract. J. Exp. Med. 122, 67-76 (1965).

10. Savage, D. C. Microbial ecology of the gastrointestinal tract. Ann. Rev. Microbiol. 31, 107-133 (1977).

11. Food and Agricultural Organization of the United Nations \& World Health Organization. Probiotics in food: Health and nutrition properties and guidelines for evaluation. FAO http://www.fao.org/3/a-a0512e.pdf (2006).

12. Hill, C. et al. Expert consensus document The International Scientific Association for Probiotics and Prebiotics consensus statement on the scope and appropriate use of the term probiotic. Nat. Rev. Gastroenterol. Hepatol. 11, 506-514 (2014).

13. Simpson, H. L. \& Campbell, B. J. Review article: dietary fibre-microbiota interactions. Aliment. Pharmacol. Ther. 42, 158-179 (2015).

14. Depeint, F., Tzortzis, G., Vulevic, J., l'Anson, K. \& Gibson, G. R. Prebiotic evaluation of a novel galactooligosaccharide mixture produced by the enzymatic activity of Bifidobacterium bifidum NCIMB 41171 , in healthy humans: a randomized, doubleblind, crossover, placebo-controlled intervention study. Am. J. Clin. Nutr. 87, 785-791 (2008).

15. Costabile, A et al. A double-blind, placebocontrolled, cross-over study to establish the bifidogenic effect of a very-long-chain inulin extracted from globe artichoke (Cynara scolymus) in healthy human subjects. Br. J. Nutr. 104, 1007-1011 (2010).

16. Roberfroid, M. et al. Prebiotic effects: metabolic and health benefits. Br. J. Nutr. 104 (Suppl. 2), S1-S63 (2010).

17. Schrezenmeir, J \& de Vrese, M. Probiotics, prebiotics, and synbiotics - approaching a definition. Am. J. Clin. Nutr. 73, 361S-364S (2001).
18. Gibson, G. R., Probert, H. M., Loo, J. V., Rastall, R. A. \& Roberfroid, M. B. Dietary modulation of the human colonic microbiota: updating the concept of prebiotics. Nutr. Res. Rev. 17, 259-275 (2004).

19. Pineiro, M. et al. FAO technical meeting on prebiotics. J. Clin Gastroenterol 42, S156-S159 (2008).

20. Gibson, G. R. et al. Dietary prebiotics: current status and new definition. Food Sci. Tech. Bull. Funct. Food 7 , 1-19 (2010)

21. Bindels, L. B., Delzenne, N. M., Cani, P. D. \& Walter, J. Towards a more comprehensive concept for prebiotics. Nat. Rev. Gastroenterol. Hepatol. 12, 303-310 (2015).

22. Dewulf, E. M. et al. Insight into the prebiotic concept: lessons from an exploratory, double blind intervention study with inulin-type fructans in obese women. Gut 62, 1112-1121 (2013).

23. Hutkins, R. W. et al. Prebiotics: why definitions matter. Curr. Opin. Biotechnol. 37, 1-7 (2016).

24. Louis, P., Flint, H. J. \& Michel, C. How to manipulate the microbiota: prebiotics. Adv. Exp. Med. Biol. 902 119-142 (2016).

25. Shannahan, F. Fibre man meets microbe man Am. J. Clin. Nutr. 10, 1-2 (2015).

26. Verspreet, J. et al. A critical look at prebiotics within the dietary fiber concept. Ann. Rev. Food Sci. Technol. 7, 167-190 (2016)

27. Vandeputte, D. et al. Prebiotic inulin-type fructans induce specific changes in the human gut microbiota. Gut http://dx.doi.org/10.1136/gutjnl-2016-313271 (2017).

28. Canfora, E. E., Jocken, J. W. \& Blaak, E. E. Shortchain fatty acids in control of body weight and insulin sensitivity. Nat. Rev. Endocrinol. 11, 577-591 (2015).

29. Koh, A., De Vadder, F., Kovatcheva-Datchary, P. $\&$ Backhed, F. From dietary fiber to host physiology: short-chain fatty acids as key bacterial metabolites. Cell 165, 1332-1345 (2016)

30. Rastall, R. A. \& Gibson, G. R. Recent developments in prebiotics to selectively impact beneficial microbes and promote intestinal health. Curr. Opin. Biotechnol. 32, 42-46 (2015)

31. Rastall, R. A. Functional oligosaccharides: application and manufacture. Ann. Rev. Food Sci. Technol. 1 , 305-339 (2010).

32. Sarbini, S. \& Rastall, R. A. Prebiotics: metabolism, structure, and function. Func. Food Rev. 3, 93-106 (2011).

33. Goh, Y. J. \& Klaenhammer, T. R. Genetic mechanisms of prebiotic oligosaccharide metabolism in probiotic microbes. Ann. Rev. Food Sci. Technol. 6, 137-156 (2015)

34. Delcour, J. A., Aman, P., Courtin, C. M., Hamaker, B. R. $\&$ Verbeke, K. Prebiotics, fermentable dietary fiber, and health claims. Adv. Nutr. 7, 1-4 (2016)

35. Ben David, Y. et al. Ruminococcal cellulosome systems from rumen to human. Environ. Microbiol. 17, 3407-3426 (2015)

36. Garrido, D. et al. Comparative transcriptomics reveals key differences in the response to milk oligosaccharides of infant gut-associated bifidobacteria. Sci. Rep. 5, 13517 (2015).

37. Oozeer, R. et al. Intestinal microbiology in early life: specific prebiotics can have similar functionalities as human-milk oligosaccharides. Am. J. Clin. Nutr. 98, 561S-571S (2013)
38. De Leoz, M. L. A. et al. Human milk glycomics and gut microbial genomics in infant feces show a correlation between human milk oligosaccharides and gut microbiota: a proof-of-concept study. J. Proteome Res. 14, 491-502 (2015)

39. Rockova, S. et al. Inter-species differences in the growth of bifidobacteria cultured on human milk oligosaccharides. Folia Microbiol. 57, 321-324 (2012).

40. He, Y., Lawlor, N. T. \& Newburg, D. S. Human milk components modulate Toll-like receptor-mediated inflammation. Adv. Nutr. 7, 102-111 (2016).

41. Kulinich, A. \& Liu, L. Human milk oligosaccharides: the role in the fine-tuning of innate immune responses Carbohydr. Res. 432, 62-70 (2016).

42. Morrow, A. L., Ruiz-Palacios, G. M., Jiang, X \& Newburg, D. S. Human-milk glycans that inhibit pathogen binding protect breast-feeding infants against infectious diarrhea. J. Nutr. 135, 1304-1307 (2005).

43. Charbonneau, M. R. et al. Sialylated milk oligosaccharides promote microbiota-dependent growth in models of infant undernutrition. Cell 164 859-871 (2016)

44. Marriage, B. J., Buck, R. H., Goehring, K. C., Oliver, J. S. \& Williams, J. A. Infants fed a lower calorie formula with 2'FL show growth and 2'FL uptake like breast-fed infants. J. Pediatr. Gastroenterol. Nutr. 61, 649-658 (2015)

45. Goehring, K. C. et al. Similar to those who are breastfed, infants fed a formula containing 2'-fucosyllactose have lower inflammatory cytokines in a randomized controlled trial. J. Nutr. 146, 2559-2566 (2016).

46. Elison, E. et al. Oral supplementation of healthy adults with 2'-O-fucosyllactose and lacto- $\mathrm{N}$-neotetraose is well tolerated and shifts the intestinal microbiota. Br. J. Nutr. 116, 1356-1368 (2016)

47. Underwood, M. A., German, J. B., Lebrilla, C. B. \& Mills, D. A. Bifidobacterium longum subspecies infantis: champion colonizer of the infant gut. Pediatr. Res. 77, 229-235 (2015).

48. Charbonneau, M. R. et al. A microbial perspective of human developmental biology. Nature 535, 48-55 (2016).

49. Clifford, M. N. Diet-derived phenols in plasma and tissues and their implications for health. Planta Med. 70, 1103-1114 (2004).

50. Duenas, M. et al. A survey of modulation of gut microbiota by dietary polyphenols. Biomed. Res. Int 2015, 850902 (2015).

51. O'Keefe, S. J. Diet, microorganisms and their metabolites, and colon cancer. Nat. Rev. Gastroenterol. Hepatol. 13, 691-706 (2016).

52. Pluznick, J. L. Gut microbiota in renal physiology: focus on short-chain fatty acids and their receptors. Kidney Int. 90, 1191-1198 (2016).

53. Boets, E. et al. Systemic availability and metabolism of colonic-derived short-chain fatty acids in healthy subjects: a stable isotope study. J. Physiol. $\mathbf{5 9 5}$ 541-555 (2017).

54. Canani, R. B. et al. Potential beneficial effects of butyrate in intestinal and extraintestinal diseases. World J. Gastroenterol. 17, 1519-1528 (2011).

55. McMillan, A. et al. A multi-platform metabolomics approach identifies highly specific biomarkers of bacterial diversity in the vagina of pregnant and non-pregnant women. Sci. Rep. 5, 14174 (2015). 
56. Vulevic, J. et al. Influence of galacto-oligosaccharide mixture (B-GOS) on gut microbiota, immune parameters and metabonomics in elderly persons. Br. J. Nutr. 114, 586-595 (2015).

57. de Preter, V. et al. Baseline microbiota activity and initial bifidobacteria counts influence responses to prebiotic dosing in healthy subjects. Aliment. Pharmacol. Ther. 27, 504-513 (2008).

58. Albert, A. Y. et al. A study of the vaginal microbiome in healthy Canadian women utilizing cpn60-based molecular profiling reveals distinct Gardnerella subgroup community state types. PLOS ONE 10, e0135620 (2015)

59. Korshonov, V. M. et al. Study of vaginal bifidoflora of women of reproductive age [Russian]. Zh. Microbiol. Epidemiol. Immunobiol. 4, 74-78 (1999).

60. Antonio, M. A., Rabe, L. K. \& Hillier, S. L. Colonization of the rectum by Lactobacillus species and decreased risk of bacterial vaginosis. J. Infect. Dis. 3, 394-398 (2005)

61. Joyce, S. A. \& Gahan, C. G. Bile acid modifications at the microbe-host interface: potential for nutraceutical and pharmaceutical interventions in host health. Ann. Rev. Food Sci. Technol. 7, 313-333 (2016).

62. Kuo, S. M., Merhige, P. M. \& Hagey, L. R. The effect of dietary prebiotics and probiotics on body weight, large intestine indices, and fecal bile acid profile in wild type and $I L 10^{-1-}$ mice. PLOS ONE 8, e60270 (2013).

63. Savignac, H. M. et al. Prebiotic administration normalizes lipopolysaccharide (LPS)-induced anxiety and cortical 5-HT2A receptor and IL1- $\beta$ levels in male mice. Brain Behav. Immunol. 52, 120-131 (2016).

64. de Cossio, L. F. et al. Impact of prebiotics on metabolic and behavioral alterations in a mouse model of metabolic syndrome. Brain Behav. Immunol. http://dx.doi.org/10.1016/j.bbi.2016.12.022 (2016).

65. Malaguarnera, M. et al. Bifidobacterium combined with fructo-oligosaccharide versus lactulose in the treatment of patients with hepatic encephalopathy. Eur. J. Gastroenterol. Hepatol. 22, 199-206 (2010).

66. Madhok, V., Futamura, M., Thomas, K. S \& Barbarot, S. What's new in atopic eczema? An analysis of systematic reviews published in 2012 and 2013. Part 2. Treatment and prevention. Clin. Exp. Dermatol. 40, 349-354 (2015).

67. Moro, G. et al. A mixture of prebiotic oligosaccharides reduces the incidence of atopic dermatitis during the first six months of age. Arch. Dis. Child. 91, 814-819 (2006).

68. Hong, K. B. et al. Photoprotective effects of galactooligosaccharide and/or Bifidobacterium longum supplementation against skin damage induced by ultraviolet irradiation in hairless mice. Int. J. Food Sci. Nutr. 66, 923-930 (2015).

69. Gao, Z., Tseng, C. H., Strober, B. E., Pei, Z $\&$ Blaser, M. J. Substantial alterations of the cutaneous bacterial biota in psoriatic lesions. PLOS ONE 3, e2719 (2008).

70. Paulino, L. C., Tseng, C. H., Strober, B. E. $\&$ Blaser, M. J. Molecular analysis of fungal microbiota in samples from healthy human skin and psoriatic lesions. J. Clin. Microbiol. 44, 2933-2941 (2006)

71. Campananti, A. et al. A novel approach to manage skin toxicity caused by therapeutic agents targeting epidermal growth factor receptor. Ann. Oncol. 23, 1081-1082 (2012).

72. Everard, A. et al. Microbiome of prebiotic-treated mice reveals novel targets involved in host response during obesity. ISME J. 8, 2116-2130 (2014).

73. Paul, H. A., Bomhof, M. R., Vogel, H. J. \& Reimer, R. A. Diet-induced changes in maternal gut microbiota and metabolomic profiles influence programming of offspring obesity risk in rats. Sci. Rep. 6, 20683 (2016).

74. Delzenne, N. M., Cani, P. D., Daubioul, C. \& Neyrinck, A. M. Impact of inulin and oligofructose on gastrointestinal peptides. Br. J. Nutr. 93, S157-S161 (2005)

75. Cani, P. D. et al. Gut microbiota fermentation of prebiotics increases satietogenic and incretin gut peptide production with consequences for appetite sensation and glucose response after a meal. Am. J. Clin. Nutr. 90, 1236-1243 (2009).

76. Parnell, J. A. \& Reimer, R. A. Weight loss during oligofructose supplementation is associated with decreased ghrelin and increased peptide $\mathrm{YY}$ in overweight and obese adults. Am. J. Clin. Nutr. 89, 1751-1759 (2009).

77. Devine, D. A. \& Marsh, P. D. Prospects for the development of probiotics and prebiotics for oral applications. J. Oral Microbiol. http://dx.doi.org 10.3402/jom.v1i0.1949 (2009).
78. van de Pol, M. A., Lutter, R. Smids, B. S Weersink, E. J. \& van der Zee, J. S. Synbiotics reduce allergen-induced T-helper 2 response and improve peak expiratory flow in allergic asthmatics. Allergy 66, 39-47 (2011).

79. Depner, M. et al. Bacterial microbiota of the upper respiratory tract and childhood asthma. J. Allergy Clin. Immunol. 6749, 30710-30712 (2016).

80. Bomar, L., Brugger, S. D., Yost, B. H., Davies, S. S. \& Lemon, K. P. Corynebacterium accolens releases antipneumococcal free fatty acids from human nostril and skin surface triacylglycerols. mBio 7, e01725-15 (2016)

81. Lozupone, C. A., Stombaugh, J. I., Gordon, J. I., Jansson, J. K. \& Knight, R. Diversity, stability and resilience of the human gut microbiota. Nature $\mathbf{4 8 9}$ 220-230 (2012)

82. Reid, G. et al. The case in favour of probiotics before during and after pregnancy: insights from the first 1,500 days. Benef. Microbes 7, 353-362 (2016).

83. Kellow, N. J., Coughlan, M. T. \& Reid, C. M Metabolic benefits of dietary prebiotics in human subjects: a systematic review of randomised controlled trials. Br. J. Nutr. 111, 1147-1161 (2014)

84. Beserra, B. T. S. et al. A systematic review and meta-analysis of the prebiotics and synbiotics effects on glycemia, insulin concentrations and lipid parameters in adult patients with overweight or obesity. Clin. Nutr. 34, 845-858 (2015).

85. Fernandes, R., do Rosario, V. A., Mocellin, M. C. Kuntz, M. G. F. \& Trindale, E. B. S. M. Effects of inulin-type fructans, galacto-oligosaccharides and related synbiotics on inflammatory markers in adult patients with overweight or obesity: a systematic review. Clin. Nutr. http://dx.doi.org/10.1016/ .clnu.2016.10.003 (2016)

86. Nicolucci, A. C. \& Reimer, R. A. Prebiotics as a modulator of gut microbiota in paediatric obesity. Ped. Obes. http://dx.doi.org/10.1111/ijpo.12140 (2016)

87. Barengolts, E. Gut microbiota, prebiotics, probiotics, and synbiotics in management of obesity and prediabetes: review of randomized controlled trials. Endocr. Pract. 22, 1224-1234 (2016).

88. Parnell, J. A., Raman, M., Rioux, K. P. \& Reimer, R. A. The potential role of prebiotic fibre for treatment and management of non-alcoholic fatty liver disease and associated obesity and metabolic syndrome. Liver Int 32, 701-711 (2012)

89. Vulevic, J., Juric, A., Tzortzis, G. \& Gibson, G. R A mixture of trans-galactooligosaccharides reduces markers of metabolic syndrome and modulates the fecal microbiota and immune function of overweight adults. J. Nutr. 143, 324-331 (2013).

90. Cani, P. D. et al. Improvement of glucose tolerance and hepatic insulin sensitivity by oligofructose requires a functional glucagon-like peptide 1 receptor. Diabetes 55, 1484-1490 (2006)

91. Verhoef, S. P., Meyer D. \& Westerterp, K. R. Effects of oligofructose on appetite profile, glucagon-like peptide 1 and peptide YY3-36 concentrations and energy intake. Br. J. Nutr. 106, 1757-1762 (2011).

92. Hume, M. P. Nicolucci, A. C. \& Reimer, R. A. Prebiotic supplementation improves appetite in children with overweight and obesity: a randomized controlled trial. Am. J. Clin. Nutr. http://dx.doi.org/10.3945/ ajcn.116.140947 (2017)

93. Schmidt, K. et al. Prebiotic intake reduces the waking cortisol response and alters emotional bias in healthy volunteers. Psychopharmacology (Berl.) 232 1793-1801 (2015)

94. Sherwin, E., Rea, K., Dinan, T. G. \& Cryan, J. F A gut (microbiome) feeling about the brain. Curr. Opin Gastroenterol. 32, 96-102 (2016).

95. Kim, Y. Y. et al. The effect of chicory fructan fibe on calcium absorption and bone metabolism in Korean postmenopausal women. Nutr. Sci. 7. 151-157 (2004).

96. Holloway, L et al. Effects of oligofructose-enriched inulin on intestinal absorption of calcium and magnesium and bone turnover markers in postmenopausal women. Br. J. Nutr. 97, 365-372 (2007).

97. McCabe, L., Britton, R. A. \& Parameswaran, N. Prebiotic and probiotic regulation of bone health: role of the intestine and its microbiome. Curr. Osteoporos. Res. 13, 363-371 (2015).

98. Firmansyah, A. et al. Fructans in the first 1000 days of life and beyond, and for pregnancy. Asia Pac. J. Clin. Nutr. 25, 652-675 (2016).
99. Abrams, S. A. et al. A combination of prebiotic shortand long-chain inulin type fructans enhances calcium absorption and bone mineralization in young adolescents. Am. J. Clin. Nutr. 82, 471-476 (2005).

100. Kano, M. et al. Consecutive intake of fermented milk containing Bifidobacterium breve strain Yakult and galacto-oligosaccharides benefits skin condition in healthy adult women. Biosci. Microbiota Food Health 32, 33-39 (2013).

101. Miyazaki, K., Masuoka, N., Kano, M. \& lizuka, R. Bifidobacterium fermented milk and galactooligosaccharides lead to improved skin health by decreasing phenols production by gut microbiota. Benef. Microbes 5, 121-128 (2014).

102. Cuello-Garcia, C. A. et al. World Allergy Organization - McMaster University guidelines for allergic disease prevention (GLAD-P): prebiotics. World Allergy Organ. J. 9, 10 (2016)

103. Osborn, D. A. \& Sinn, J. K. Prebiotics in infants for prevention of allergy. Cochrane Database Syst. Rev. 3 , CD006474 (2013)

104. Dang, D. et al. Meta-analysis of probiotics and/or prebiotics for the prevention of eczema. J. Int. Med. Res. 41, 1426-1436 (2013).

105. Boyle, R. J. et al. Prebiotic-supplemented partially hydrolysed cow's milk formula for the prevention of eczema in high-risk infants: a randomized controlled trial. Allergy 71, 701-710 (2016).

106. Ghouri, Y. A. et al. Systematic review of randomized controlled trials of probiotics, prebiotics and synbiotics in inflammatory bowel disease. Clin. Exp. Gastroenterol. 7, 473-487 (2014)

107. Coste, I., Judlin, P., Lepargneur, J.-P. \& Bou-Antoun, S Safety and efficacy of an intravaginal prebiotic ge in the prevention of recurrent bacterial vaginosis: a randomized double-blind study. Obstet. Gynecol. Int 2012, 147867 (2012).

108. Giovannini, M. et al. Prebiotic effect of an infant formula supplemented with galacto-oligosaccharides: randomized multicenter trial. J. Am. Coll. Nutr. 33. 385-393 (2014)

109. Radke, M. et al. Starter formula enriched in prebiotics and probiotics ensures normal growth of infants and promotes gut health: a randomized clinical trial. Pediatr. Res. 81, 622-631 (2016).

110. Martinez, R. C. R., Bedani, R. \& Saad, S. M. I. Scientific evidence for the health effects attributed to the consumption of probiotics and prebiotics: an update for current perspectives and future challenges. Br. J. Nutr. 114, 1993-2015 (2015).

111. Valdez, Y., Brown, E. M. \& Finlay, B. B. Influence of the microbiota on vaccine effectiveness. Trend. Immunol. 35, 526-537 (2014).

112. Lohner, S., Kullenberg, D., Antes, G., Decsi, T \& Meerpohl, J. J. Prebiotics in healthy infants and children for prevention of acute infectious diseases: a systematic review and meta-analysis. Nutr. Rev. 8 523-531 (2014)

113. Chatchatee, P. et al. Effects of growing-up milk supplemented with prebiotics and LCPUFAs on infections in young children. J. Ped. Gastroenterol. Nutr. 58, 428-437 (2014).

114. Luoto, R. et al. Prebiotic and probiotic supplementation prevents rhinovirus infections in preterm infants: a randomized, placebo-controlled trial. J. Allergy Clin. Immunol. 133, 405-413 (2014).

115. Armanian, A. M. et al. The effect of neutral oligosaccharides on reducing the incidence of necrotizing enterocolitis in preterm infants: a randomized clinical trial. Int. J. Prev. Med. 5 1387-1395 (2014)

116. Silk, D. B., Davis, A., Vulevic, J., Tzortzis, G $\&$ Gibson, G. R. Clinical trial: the effects of a trans-galactooligosaccharide prebiotic on faecal microbiota and symptoms in irritable bowel syndrome Alim. Pharm. Ther. 29, 508-518 (2009).

117. Drakoularakou, A., Tzortzis, G., Rastall, R. A. \& Gibson, G. R. A double-blind, placebo-controlled, randomized human study assessing the capacity of a novel galacto-oligosaccharide mixture in reducing travellers' diarrhoea. Eur. J. Clin. Nutr. 64, 146-152 (2010).

118. Christodoulides, S. et al. Systematic review with meta-analysis: effect of fibre supplementation on chronic idiopathic constipation in adults. Aliment. Pharmacol. Ther. 44, 103-116 (2016).

119. Closa-Monasterolo, R. et al. The use of inulin-type fructans improves stool consistency in constipated children. A randomised clinical trial: pilot study. Int. J. Food Sci. Nutr. 8, 1-11 (2016). 
120. Vulevic, J., Drakoularakou, A., Yaqoob, P., Tzortzis, G $\&$ Gibson, G. R. Modulation of the fecal microflora profile and immune function by a novel transgalactooligosaccharide mixture (B-GOS) in healthy elderly volunteers. Am. J. Clin. Nutr. 88, 1438-1446 (2008).

121. Matsuki, T. et al. A key genetic factor for fucosyllactose utilization affects infant gut microbiota development. Nat. Commun. 7, 11939 (2016).

122. Marques, T. M. et al. Programming infant gut microbiota: influence of dietary and environmental factors. Curr. Opin. Biotechnol. 21, 149-156 (2010).

123. Blaser, M. J. Antibiotic use and its consequences for the normal microbiome. Science 352, 544-545 (2016).

124. Rogler, G., Zeitz, J. \& Biedermann, L. The search for causative environmental factors in inflammatory bowel disease. Dig. Dis. 34, 48-55 (2016).

125. Griffin, N. W. et al. Prior dietary practices and connections to a human gut microbial metacommunity alter responses to diet interventions. Cell Host Microbe 21, 84-96 (2017).

126. Stevens, C. E. \& Hume, I. D. Contributions of microbes in vertebrate gastrointestinal tract to production and conservation of nutrients. Physiol. Rev. 78, 393-427 (1998).

127. Respondek, F. et al. Short-chain fructooligosaccharides influence insulin sensitivity and gene expression of fat tissue in obese dogs. J. Nutr. 138, 1712-1718 (2008).

128. Apanavicius, C. J. et al. Fructan supplementation and infection affect food intake, fever, and epithelial sloughing from salmonella challenge in weanling puppies. J. Nutr. 137, 1923-1930 (2007).

129. Gouveia, E. M. M. F. et al. Action of phosphorylated mannanoligosaccharides on immune and hematological responses and fecal consistency of dogs experimentally infected with enteropathogenic Escherichia coli strains. Braz. J. Microbiol. 44 499-504 (2013)

130. Kanakupt, K., Vester Boler, B. M., Dunsford, B. R \& Fahey, G. C. Jr. Effects of short-chain fructooligosaccharides and galactooligosaccharides, individually and in combination, on nutrient digestibility, fecal fermentative metabolite concentrations, and large bowel microbial ecology of healthy adults cats. J. Anim. Sci. 89, 1376-1384 (2011).

131. Verbrugghe, A. et al. Oligofructose and inulin modulate glucose and amino acid metabolism through propionate production in normal-weight and obese cats. J. Nutr. 102, 694-702 (2009).

132. Correa-Matos, N. J. et al. Fermentable fiber reduces recovery time and improves intestinal function in piglets following Salmonella typhimurium infection. J. Nutr. 133, 1845-1852 (2003).

133. Liu, P. et al. Effects of chito-oligosaccharide supplementation on the growth performance, nutrient digestibility, intestinal morphology, and fecal shedding of Escherichia coli and Lactobacillus in weaning pigs. J. Anim. Sci. 86, 2609-2618 (2008).

134. Che, T. M. et al. Mannan oligosaccharide improves immune responses and growth efficiency of nursery pigs experimentally infected with porcine reproductive and respiratory syndrome virus. J. Anim. Sci. 89, 2592-2602 (2011)

135. Halas, V. \& Nochta, I. Mannan oligosaccharides in nursery pig nutrition and their potential mode of action. Animals 23, 261-274 (2012).

136. Quigley, J. D. III, Drewry, J. J., Murray, L. M. \& Ivey, S. J. Body weight gain, feed efficiency, and fecal scores of dairy calves in response to galactosyl-lactose or antibiotics in milk replacers. J. Dairy Sci. $\mathbf{8 0}$ 1751-1754 (1997).
137. Ghosh, S. \& Mehla, R. K. Influence of dietary supplementation of prebiotics (mannanoligosaccharide) on the performance of crossbred calves. Trop. Anim. Health Prod. 44, 617-622 (2012).

138. Roodposhti, P. M. \& Dabiri, N. Effects of probiotic and prebiotic on average daily gain, fecal shedding of Escherichia coli, and immune system status in newborn female calves. Asian-Australas. J. Anim. Sci. 25, 1255-1261 (2012).

139. Baines, D. \& Erb, S. Characterization of Shiga toxinproducing Escherichia coli infections in beef feeder calves and the effectiveness of a prebiotic in alleviating Shiga toxin-producing Escherichia coli infections. Ir. Vet. J. 66, 17 (2013).

140. Ortiz, L. T., Rodríguez, M. L., Alzueta, C., Rebolé, A. \& Treviño, J. Effect of inulin on growth performance, intestinal tract sizes, mineral retention and tibial bone mineralization in broiler chickens. Br. Poult. Sci. 50, 325-332 (2009).

141. Sohail, M. U. et al. Effect of supplementation of prebiotic manna-oligosaccharides and probiotic mixture on growth performance of broilers subjected to chronic heat stress. Poult. Sci. 91, 2235-2240 (2012).

142. Shanmugasundaram, R., Sifri, M. \& Selvaraj, R. K Effect of yeast cell product supplementation on broiler cecal microflora species and immune responses during an experimental coccidial infection. Poult. Sci. 92 , 1195-1201 (2013)

143. Cho, J. H. \& Kim, I. H. Effects of lactulose supplementation on performance, blood profiles, excreta microbial shedding of Lactobacillus and Escherichia coli, relative organ weight and excreta noxious gas contents in broilers. J. Anim. Physiol. Anim. Nutr 98, 424-430 (2014).

144. Roto, S. M., Kwon, Y. M. \& Ricke, S. C. Applications of in ovo technique for the optimal development of the gastrointestinal tract and the potential influence on the establishment of its microbiome in poultry. Front. Vet. Sci. 3, 63 (2016)

145. Pruszynska-Oszmalek, E. et al. In ovo injection of prebiotics and synbiotics affects the digestive potency of the pancreas in growing chickens. Poult. Sci. 94 1909-1916 (2015)

146. Bednarczyk, M. et al. Influence of different prebiotics and mode of their administration on broiler chicken performance. Animal 10, 1271-1279 (2016).

147. Li, P. et al. Dietary supplementation of short-chain fructooligosaccharides influences gastrointestinal microbiota composition and immunity characteristics of Pacific white shrimp. Litopenaeus vannamei, cultured in a recirculating system. J. Nutr. 137, 2763-2768 (2007)

148. Hoseinifar, S. H., Khalili, M., Rostami, H. K. \& Esteban, M. A. Dietary galactooligosaccharide affects intestinal microbiota, stress resistance, and performance of Caspian roach (Rutilus rutilus) fry. Fish Shellfish Immunol. 35, 1416-1420 (2013).

149. Hoseinifar, S. H., Soleimani, N. \& Ringø, E. Effects of dietary fructo-oligosaccharide supplementation on the growth performance, haemato-immunological parameters, gut microbiota and stress resistance of common carp (Cyprinus carpio) fry. Br. J. Nutr. 112, 1296-1302 (2014).

150. Morgan, L. M., Coverdale, J. A., Froetschel, M. A \& Yoon, I. Effect of yeast culture supplementation on digestibility of varying forage quality in mature horses. J. Equine Vet. Sci. 27, 260-265 (2007).

151. Respondek, F., Goachet, A. G. \& Julliand, V. Effects of dietary short-chain fructooligosaccharide on the intestinal microflora of horses subjected to a sudden change in diet. J. Anim. Sci. 86, 316-323 (2008)
152. Respondek, F., Myers, K., Smith, T. L., Wagner, A $\S$ Geor, R. J. Dietary supplementation with short-chain fructooligosaccharides improves insulin sensitivity in obese horses. J. Anim. Sci. 89, 77-83 (2011).

153. EFSA NDA Panel (EFSA Panel on Dietetic Products, Nutrition and Allergies). Scientific Opinion on the substantiation of a health claim related to "native chicory inulin" and maintenance of normal defecation by increasing stool frequency pursuant to Article 13.5 of Regulation (EC) No 1924/2006. EFSA https://www.efsa.europa.eu/en/efsajournal/pub/3951 (2015).

154. EFSA NDA Panel (EFSA Panel on Dietetic Products, Nutrition and Allergies). Guidance on the preparation and presentation of an application for authorisation of a novel food in the context of Regulation (EU) 2015/2283. EFSA J. 14, 4594-4624 (2016).

155. U.S. Food and Drug Administration. Draft guidance for industry: dietary supplements: new dietary ingredient notifications and related issues. FDA http://www.fda.gov/food/guidanceregulation/ guidancedocumentsregulatoryinformation/ dietarysupplements/ucm257563.htm (2016).

156. U.S. Food and Drug Administration. Changes to the nutrition factors label. FDA http://www.fda.gov/Food/GuidanceRegulation/ GuidanceDocumentsRegulatoryInformation/ LabelingNutrition/ucm385663.htm (2014).

\section{Acknowledgements}

The authors would like to thank members of the International Scientific Association for Probiotics and Prebiotics (ISAPP) board of directors who did not directly participate in this consensus panel, but who reviewed, criticized and approved the manuscript: D. Merenstein (Georgetown University Medical Center, USA), M. Cabana (University of California, San Francisco, USA), S. Lebeer (University of Antwerp, Belgium), E. Quigley (The Methodist Hospital and Weill Cornell School of Medicine, USA) and C. Hill (University College Cork, Ireland). We also gratefully acknowledge D. Mills (University of California at Davis, USA) for his constructive comments. Gratitude is expressed to ISAPP for funding travel and meeting expenses associated with conducting this panel.

\section{Author contributions}

Individual author sections were compiled by G.R.G., M.E.S and G.R. All co-authors reviewed and edited the manuscript before submission.

Competing interests statement

G.R.G., R.H., M.E.S., S.J.S., K.S. and G.R. declare associations with the ISAPP. G.R.G., R.H., M.E.S., S.L.P., R.A.R., S.J.S. K.S., K.S.S, P.D.C., K.V., G.R. declare associations with other companies and/or organizations. See the article online for full details of the relationships. C.S. declares no competing interests.

Publisher's note

Springer Nature remains neutral with regard to jurisdictional claims in published maps and institutional affiliations.

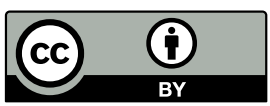

This work is licensed under a Creative Commons Attribution 4.0 International License. The images or other third party material in this article are included in the article's Creative Commons license, unless indicated otherwise in the credit line; if the material is not included under the Creative Commons license, users will need to obtain permission from the license holder to reproduce the material. To view a copy of this license, visit http://creativecommons.org/licenses/by/4.0/. 